\title{
Example of a Pelvis Deformed in Consequence of Infantile Paralysis.*
}

By J. B. Hellater, M.D. (Lond.), Honorary Obstetric Physician, Leeds Infirmary; Lecturer on Gynacology in the University of Leeds.

The variety of pelvic deformity which results from infantile palsy of one lower extremity does not receive much attention in English text-books of obstetrics. The best account of this subject that I have been able to find occurs in the third volume of Tarnier and Budin's Traité de l'Art des Accouchements. I reproduce here a diagrammatic sketch of the condition under consideration. (See Fig. 1). These are twofold:--(1) There is deficient development of the os innominatum of the paralysed side. (2) The normal physiological flattening which usually takes place between birth and maturity under gravity, is deficient or wanting on the paralysed side and exaggerated on the other side. This is due to the non-use of the paralysed leg and the consequent absence of pressure on the acetabulum. The weight being thrown on the sound side there is flattening of the pelvis on that side and an oblique deformity is caused. If, however, the affected leg should not have been wholly useless but have borne some appreciable amount of weight, it may be found that owing to the tenuity and weakness of the bone, the pelvis has yielded a good deal on the palsied side. This is not the case in the pelvis which $I$ am about to describe, which corresponds very closely with the sketch shown, except that the left side and not the right is affected.

This pelvis came from a subject in the dissecting-room at the Leeds University, and I am indebted to Professor Wardrop Griffith and to Dr. J. K. Jamieson (who made the preparation) for the opportunity of showing it before this Society. The patient was a male, 39 years old, who died from phthisis. The left limb was shorter than the other by four inches, and was much atrophied, the sacral plexus was atrophic on the left and the obturator internus and pyriformis were scarcely to be found. The psoas was well developed. The patient had walked with a crutch. [The sacrum has been damaged during the excision of the spinal cord.]

* A paper read at the meeting of the North of England Obstetrical Society, anuary 19th, 1906. 
Description of pelvis. On comparing the two ossa innominata it will be seen that the left is everywhere smaller and thinner than the other, owing to the atrophy consequent upon the anterior poliomyelitis. The difference is most marked in the ischia. The right ischio-pubic ramus has a breadth of $\frac{5}{8} \mathrm{in}$., while at the corresponding point the left is reduced to a slender shaft $3 / 16$ in. broad. The distance on the right side from the ilio-pectineal line to the lowest point of the tuber ischii is $4 \mathrm{in}$., but on the left is $\frac{7}{8} \mathrm{in}$. less, and the contrast between the two tubera ischii is most striking. The iliac bone with its crests and spines is everywhere smaller on the left side. The distance from the anterior to the posterior iliac spine is $6 \frac{3}{4}$ ins. on the right and $5 \frac{3}{4} \mathrm{ins}$. on the left, and the iliac crest is $\frac{7}{8} \mathrm{in}$. further from the ilio-pectineal line on the right than the left. The acetabulum is also somewhat smaller on the left.

Turning to the shape of the pelvis as a whole, we note that the left half of the pelvic brim is rounded, and that the right.is flattened, so that the oblique diameter of the brim measured from the right sacro-iliac synchondrosis is 5 ins. against $4 \frac{1}{2}$ ins. in the opposite oblique diameter. The distance from the centre of the sacral promontory to the centre of the ilio-pubic ramus is $3 \frac{1}{2}$ ins. on the right, and $4 \frac{1}{2}$ ins. on the left. The lower two lumbar vertebræ, which are included in the specimen, show indications of some degree of lateral curve, and the shape of the pelvis is somewhat oblique.

The sacrum shows little or no atrophy due to the palsy, but on the right side, where the weight was borne, the width of the wing of the sacrum is $1 \frac{1}{8}$ ins. against $1 \frac{1}{4}$ ins. on the palsied side, so that this measurement is less on the sound side.

The outlet of the pelvis is diminished. The distance between the ischial spines is $3 \frac{1}{4}$ ins., and the lower end of the sacrum and the coccyx curve so far forwards that the tip of the coccyx comes within $1 \frac{3}{4}$ ins. of the symphysis. This tip deviates to the right, being 1 in. from the right ischio-pubic ramus and $1 \frac{3}{4}$ ins. from the left.

I think that this pelvis furnishes a specimen of considerable obstetrical interest, in spite of the fact that it comes from a male subject.

\section{Tarle of Measurements.}

$\begin{array}{llllllllll}\text { Shortening of left } \operatorname{leg} & \ldots & \ldots & \ldots & \ldots & \ldots & \ldots & \ldots & \ldots & \end{array} 4 \mathrm{in.}$

Right. Left.

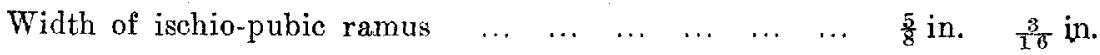

From ilio-pectineal line to lowest point of tuber ischii ... 4 in. $3 \frac{1}{8}$ in.

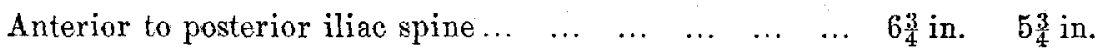




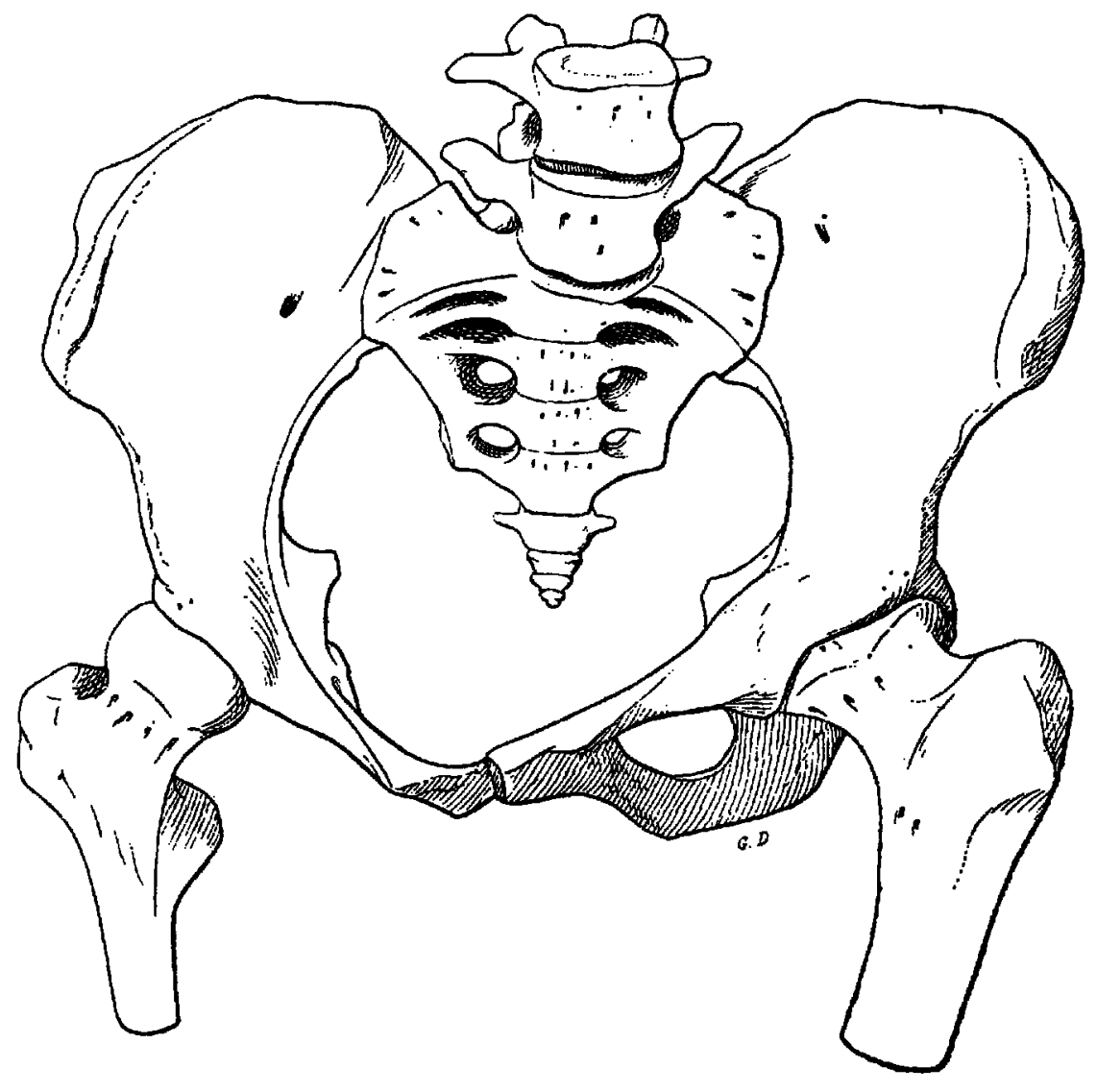

Fig. 1. 


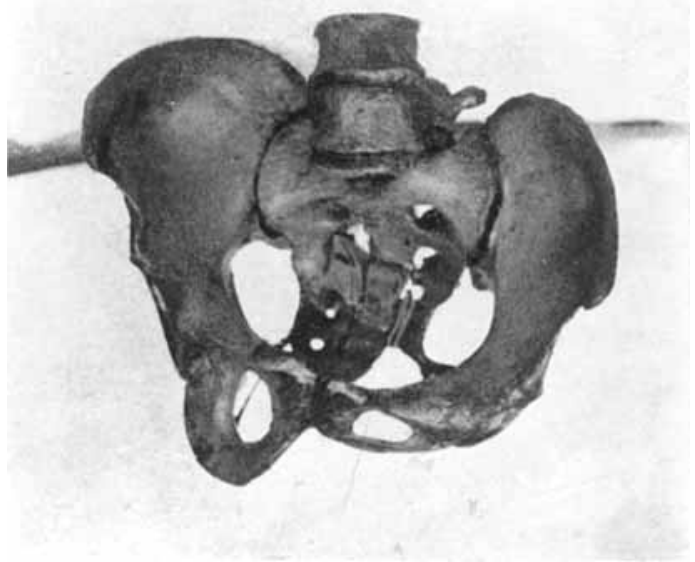

Fig. 2.

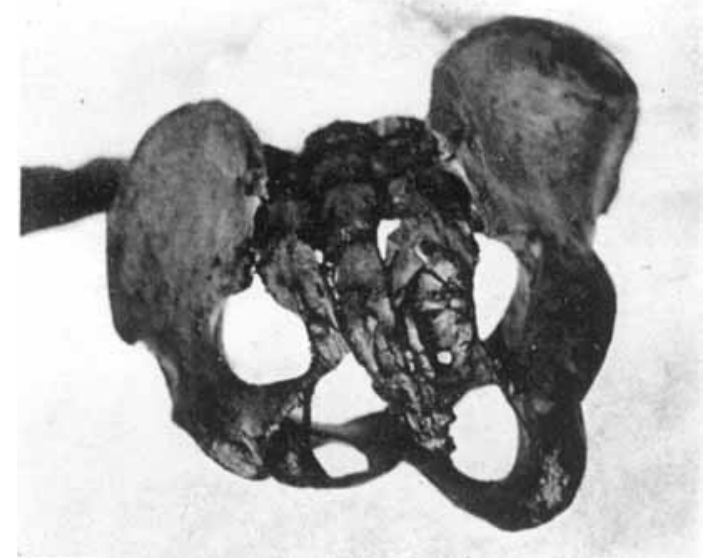

Fig. 3.

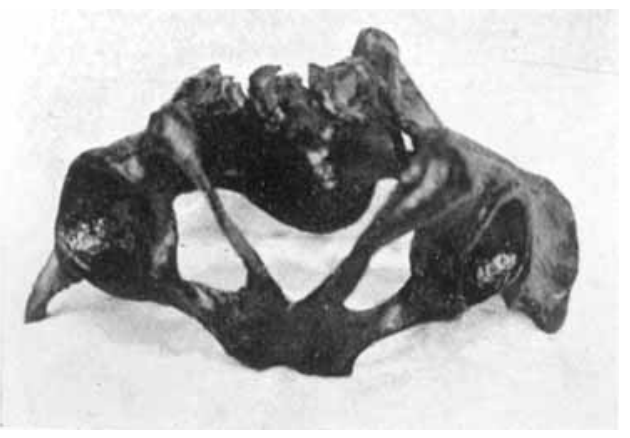

Fig. 4. 


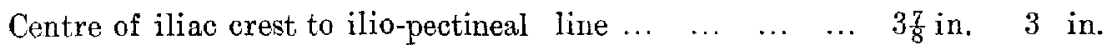

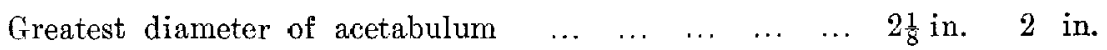

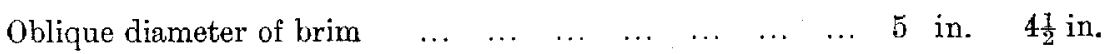
Centre of sacral promontory to centre of ilio-pubic ramus $3 \frac{1}{2} \mathrm{in} . \quad 4 \frac{1}{2} \mathrm{in}$.

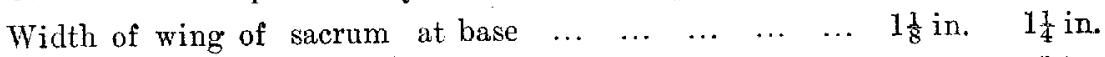
Tip of coccyx to ischio-pubic ramus $\ldots \begin{array}{llllllll}\ldots & \ldots & \ldots & \ldots & 1 & \text { in. } & 1 \frac{3}{4} & \text { in. }\end{array}$

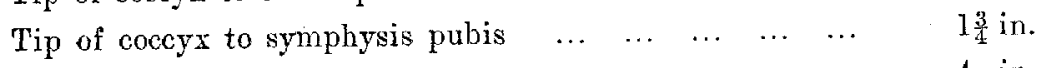
$\begin{array}{llllllllll}\text { True conjugate of brim } & \ldots & \ldots & \ldots & \ldots & \ldots & \ldots & \ldots & & 4 \text { in. }\end{array}$ $\begin{array}{llllllllll}\text { Oblique conjugate } \ldots & \ldots & \ldots & \ldots & \ldots & \ldots & \ldots & \ldots & \ldots & 4 \frac{1}{2} \mathrm{in} .\end{array}$

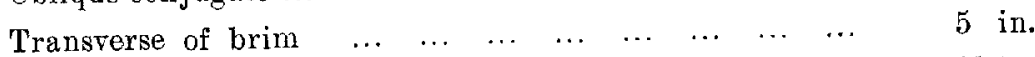

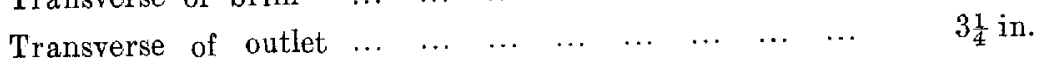

Explanation of Frgures.

Figure 1. Sketch of a female pelvis deformed in consequence of infantile palsy on the right side. T'aken from Tarnier et Budin, Traité de l'Art des Accouchements, Tome iii., p. 257, Paris, 1898.

Figure 2. Photograph of the male pelvis described in this paper. Note especially the small size of the left ilium, pubes and ischium, the deviation of the sacrum to the right, the relative flattening of the pelvic brim on the right, and the less width of the sacral wing on this side.

Figure 3. The same seen from behind (the sacral spines have been removed). Note especially the contrast between the tubera ischii.

Figure 4. The same. Pelvic outlet seen from below. Note the relative size of the right and left posterior iliac spines.

(Photographs taken by Mr. Oliver, of the Leeds Infirmary.) 